\title{
Radiation measurements at ICOS ecosystem stations
}

\author{
Arnaud Carrara ${ }^{1}$, Pasi Kolari ${ }^{2}$, Maarten Op de Beeck ${ }^{3}$, Nicola Arriga ${ }^{3}$, Daniel Berveiller ${ }^{4}$, \\ Sigrid Dengel ${ }^{5}$, Andreas Ibrom ${ }^{6}$, Lutz Merbold ${ }^{7,8}$, Corinna Rebmann ${ }^{9}$, Simone Sabbatini ${ }^{10}$, \\ Penelope Serrano-Ortíz ${ }^{11}$, and Sébastien C. Biraud ${ }^{5}$
}

\begin{abstract}
${ }^{1}$ Mediterranean Center for Environmental Studies (CEAM), C/ Charles R. Darwin 14, Parque Tecnológico 46980, Paterna, Spain
${ }^{2}$ Institute for Atmosphere and Earth System Research/ Physics, PO Box 68, Faculty of Science, University of Helsinki, Finland

${ }^{3}$ Research Centre of Excellence Plants and Ecosystems (PLECO), University of Antwerp, Wilrijk, Belgium

${ }^{4}$ Ecologie Systématique et Evolution, Univ. Paris-Sud, CNRS, AgroParisTech, Université Paris-Saclay, 91400 Orsay, France

${ }^{5}$ Climate Sciences Department, Lawrence Berkeley National Laboratory, 1 Cyclotron Road, Berkeley, CA 94720, USA

${ }^{6}$ Department of Environmental Engineering, Technical University of Denmark, Bygningstorvet, 2800 Kgs. Lyngby, Denmark

${ }^{7}$ Institute of Agricultural Sciences, ETH Zurich, Universitätstrasse 2, 8092, Zurich, Switzerland

${ }^{8}$ Mazingira Centre, International Livestock Research Institute (ILRI), P.O. Box 102 30709, 00100, Nairobi, 103 Kenya

${ }^{9}$ Department Computational Hydrosystems, Helmholtz Centre for Environmental Research - UFZ, Permoserstraße 15,

04318, Leipzig, Germany

${ }^{10}$ Department for Innovation in Biological, Agro-food and Forest Systems (DIBAF), University of Tuscia, Largo dell’Università Blocco D, 01100, Viterbo, Italy

${ }^{11}$ Department of Ecology, University of Granada, 18071, Granada, Spain
\end{abstract}

Received April 12, 2018; accepted October 1, 2018

\begin{abstract}
Solar radiation is a key driver of energy and carbon fluxes in natural ecosystems. Radiation measurements are essential for interpreting ecosystem scale greenhouse gases and energy fluxes as well as many other observations performed at ecosystem stations of the Integrated Carbon Observation System (ICOS). We describe and explain the relevance of the radiation variables that are monitored continuously at ICOS ecosystem stations and define recommendations to perform these measurements with consistent and comparable accuracy. The measurement methodology and instruments are described including detailed technical specifications. Guidelines for instrumental set up as well as for operation, maintenance and data collection are defined considering both ICOS scientific objectives and practical operational constraints. For measurements of short-wave (solar) and long wave (infrared) radiation components, requirements for the ICOS network are based on available well-defined state-of-the art standards (World Meteorological Organization, International Organization for Standardization). For photosynthetically active radiation measurements, some basic instrumental requirements are based on the performance of commercially available sensors. Since site specific conditions and practical constraints at individual
\end{abstract}

*Corresponding author e-mail: arnaud@ceam.es
ICOS ecosystem stations may hamper the applicability of standard requirements, we recommend that ICOS develops mid-term coordinated actions to assess the effective level of uncertainties in radiation measurements at the network scale.

Keyw ords: ICOS, standard, radiation, measurement, PAR

\section{INTRODUCTION}

Solar incoming radiation drives almost every known physical and biological cycle in the earth system. In terrestrial ecosystems, solar incoming radiation influences energy, water and carbon balances at the earth's surface. The net radiation, which is the difference between incoming and outgoing radiation, constitutes the fundamental input to the surface energy budget and determines the quantity of energy available for heat storage and transfer to the atmosphere as radiative energy and turbulent fluxes of latent and sensible heat (Foken, 2008a; Bonan, 2008). Solar radiation controls temporal temperature patterns from daily to seasonal time scales and the water cycle at ecosystem scale 
by affecting both evaporation rate from surfaces (i.e. soil, vegetation, water bodies) and transpiration rates through stomatal closure.

Radiation is therefore a key variable that heavily influences energy and carbon fluxes at ecosystem scale directly through the process of photosynthesis which allows plants to convert radiation energy into chemical energy to form photosynthates such as carbohydrates and proteins (Emerson, 1958; Govindjee, 1982; Amesz, 1987; Barber, 1992). Similarly, radiation indirectly controls ecosystem temperature and water status, which are two parameters that affect photosynthetic assimilation processes (Baker, 1996) as well as respiratory processes (Luo and Zhou 2006; Reichstein et al., 2002; Rutledge et al., 2010). Therefore, radiation data are essential for interpreting and understanding trends in ecosystem fluxes that will be detected by the Integrated Carbon Observation System (ICOS) long-term observation program. Radiation measurements are by far not trivial and standardization is needed to reach comparability across different monitoring stations in a network or an environmental research infrastructure such as ICOS. We describe here the standard methodology and requirements for the measurement of radiation variables at ICOS terrestrial ecosystem stations.

\section{Radiation variables}

The radiation variables (i.e. radiometric quantities) that will be measured at ICOS ecosystem stations are all irradiances. The irradiance $E$, at a point on a surface, is defined as (ISO 80000-7:2008, item 7-19):

$$
E=d \Phi / d A,
$$

where: $d \Phi$ is the radiant flux incident on an element of the surface with area $d A$. In the International System of Units (SI), $E$ is expressed in $\mathrm{W} \mathrm{m}^{-2}$.

The radiation quantities at the earth's surface are classified into two groups according to their origin and spectral nature, namely solar (also called short-wave) and terrestrial (also called long-wave) radiation. Since the spectral distributions of solar and terrestrial radiation overlap very little, they are usually measured and treated separately (WMO, 2008; Vignola et al., 2012).

\section{Short-wave (solar) radiation}

Solar radiation is the electromagnetic energy emitted by the sun. The solar radiation incident just above the earth's atmosphere is called extraterrestrial solar radiation. The spectral distribution of the sun's radiation is similar to that of a black body at $5778 \mathrm{~K}$ (Johnson, 1954; Gueymard, 2018 ), and approximately $96 \%$ of the complete extraterrestrial solar radiation is confined to the spectral range from 0.3 to $3 \mu \mathrm{m}$ (Wehrli, 1985; Wielicki et al., 2013). Part of the extraterrestrial solar radiation penetrates through the atmosphere to the earth's surface without being scattered or absorbed. This "beam" radiation coming from the direction of the sun is called direct normal irradiance (DNI; ISO9488, 1999; Blanc et al., 2014). It is the energy flux density of the solar radiation incoming from the solid angle subtended by the sun's disk on a unitary surface perpendicular to the rays. Another part of the sun's radiation reaches the earth's surface after being scattered in the atmosphere by the gas molecules, aerosol particles and clouds. It is called diffuse horizontal irradiance (DHI; Bird and Riordan, 1986). The total amount of solar radiation on a horizontal surface is called the global horizontal irradiance (GHI; Quasching, 2003). The term "global" is associated to the fact that the solar radiation is received from the entire $2 \pi \mathrm{sr}$ solid angle of the sky vault. Since the energy flux density on a plane surface is directly proportional to the cosine of the angle between the normal to the surface and the incidence angle, the $G H I$ is equal to the direct normal irradiance times the cosine of the solar zenith angle ( $s z a)$ plus the diffuse irradiance:

$$
G H I=D N I^{*} \cos (s z a)+D H I .
$$

Long-wave (infrared) radiation

Terrestrial infrared radiation is the electromagnetic energy emitted by the earth's surface and by the gases, aerosols and clouds of the atmosphere. For the earth's surface and atmospheric temperatures (typically within the range 230$330 \mathrm{~K}$ ), this emitted radiation is in the infrared (IR) spectral domain (3 to $100 \mu \mathrm{m}$ ) and is commonly named long-wave radiation. The radiation emitted by earth's surface is named long-wave upward radiation or surface infrared radiation, while the radiation emitted by the atmosphere is named long-wave downward radiation or atmospheric infrared radiation. For a temperature of $300 \mathrm{~K}, 99.99 \%$ of the power of the terrestrial radiation has a wavelength longer than $3 \mu \mathrm{m}$ and about $99 \%$ longer than $5 \mu \mathrm{m}$.

\section{Photosynthetically active radiation}

The photosynthetically active radiation (PAR) designates the spectral range of solar radiation that photosynthetic organisms are able to use in the process of photosynthesis. The most commonly accepted spectral interval to define $P A R$ is from 400 to $700 \mathrm{~nm}$ (McCree, 1972a; Ross and Sulev, 2000). PAR can then be expressed simply in terms of energy as the integrated irradiance between the wavelength 400 and $700 \mathrm{~nm}$, in units of $\mathrm{W} \mathrm{m}^{-2}$, such as:

$$
P A R=\int_{400 \mathrm{~nm}}^{700 \mathrm{~nm}} I(\lambda) d \lambda,
$$

where: $I(\lambda)$ is the spectral distribution of irradiance as function of wavelength $\lambda\left(\mathrm{W} \mathrm{m}^{-2} \mathrm{~nm}^{-1}\right)$.

Photosynthesis is a quantum process, meaning that individual photons produce the reactions that occur in plants photosystems to convert radiation energy into chemical energy to form photosynthates. Therefore, $P A R$ is generally measured in terms of photons per unit time per unit 
area, and the measured variable is then the photosynthetic photon flux density (PPFD). PPFD, in units of photons $\mathrm{m}^{-2}$ $\mathrm{s}^{-1}$, is defined as:

$$
P P F D=\frac{1}{h c} \int_{400 n m}^{700 n m} \lambda I(\lambda) d \lambda,
$$

where: $h$ is the Planck's constant $\left(6.62610^{-34} \mathrm{~J} \mathrm{~s}\right)$ and $c$ is the speed of light $\left(2.99810^{8} \mathrm{~m} \mathrm{~s}^{-1}\right)$.

In order to make the numbers convenient to work with, the $P P F D$ is generally expressed in units of $\mu \mathrm{mol}$ photons $\mathrm{m}^{-2} \mathrm{~s}^{-1}$, such as:

$$
P P F D=\frac{10^{6}}{h c N_{A}} \int_{400 n m}^{700 n m} \lambda I(\lambda) d \lambda,
$$

where: $N_{A}$ is the Avogadro constant $\left(6.02210^{23} \mathrm{~mol}^{-1}\right)$.

It is well known that plants vary in the sensitivity of the photosynthetic apparatus (i.e. quantum yield of photosynthesis) to radiation of different wavelengths (Rabinowitch, 1951; Emerson, 1958). As shown by McCree (1972b), the photosynthetic response of plants correlates better with the number of photons (i.e. PPFD) than with energy (i.e. PAR). As a consequence, the photon flux density in the waveband 400 to $700 \mathrm{~nm}$ can be considered an adequate standard measurement of PAR for most ecophysiological studies (McCree, 1981).

The photosynthetically active radiation variable to be measured at ICOS stations is the photosynthetic photon flux density PPFD, expressed in units of $\mu$ mol photons $\mathrm{m}^{-2} \mathrm{~s}^{-1}$, such as defined in Eq. (5).

At ICOS terrestrial ecosystem stations, the radiation quantities considered are the following:

- The global horizontal irradiance (GHI) (i.e. shortwave downward irradiance) for which the ICOS variable name is "incoming short-wave radiation" $\left(S W_{-} I N\right)$.

- The reflected solar radiation (i.e. short-wave upward irradiance) received from the entire $2 \pi$ sr solid angle of the terrestrial surface, for which the ICOS variable name is "outgoing short-wave radiation" (SW_OUT).

- The diffuse horizontal irradiance $(D H I)$ for which the ICOS variable name is "diffuse short-wave radiation" (SW_DIF).

- The long-wave downward irradiance received from the entire $2 \pi$ sr solid angle of the sky vault for which the ICOS variable name is "incoming long-wave radiation" $\left(L W_{-} I N\right)$.

- The long-wave upward irradiance received from the entire $2 \pi$ sr solid angle of the terrestrial surface, for which the ICOS variable name is "outgoing long-wave radiation" (LW_OUT).

- The downward photosynthetic photon flux density received from the entire $2 \pi$ sr solid angle of the sky vault for which the ICOS variable name is "incoming photosynthetic photon flux density" (PPFD_IN).
- The upward photosynthetic photon flux density received from the entire $2 \pi \mathrm{sr}$ solid angle of the terrestrial surface for which the ICOS variable name is "outgoing photosynthetic photon flux density" (PPFD_OUT).

- The downward diffuse photosynthetic photon flux density received from the entire $2 \pi \mathrm{sr}$ solid angle of the sky vault for which the ICOS variable name is "diffuse photosynthetic photon flux density" ( $\left.P P F D \_D I F\right)$.

- The downward photosynthetic photon flux density received at soil surface (i.e. below aboveground vegetation) for which the ICOS variable name is "below canopy photosynthetic photon flux density" (PPFD_BC_IN).

- The net radiation (NETRAD), that is defined and will be calculated as the algebraic sum of the incoming shortwave radiation, the outgoing short-wave radiation, the incoming long-wave radiation, and the outgoing long-wave radiation (Vignola et al., 2012):

$$
N E T R A D=S W_{-} I N-S W_{-} O U T+L W_{-} I N-L W_{-} O U T \text {. }
$$

Table A1 summarizes the radiation quantities considered at ICOS ecosystem stations and their maximum expected range at the earth`s surface.

\section{METHODOLOGY}

\section{Measurement methods and instrumentation}

The selection of radiometric sensors is crucial to achieve high quality radiation measurements of comparable accuracy within the ICOS ecosystem network. The technical specifications of the sensors employed at ICOS ecosystem stations must fulfil minimum requirements that are detailed below for all radiation variables.

Incoming and outgoing short-wave radiation (SW_IN and $\left.S W \_O U T\right)$

The instruments used to measure short-wave radiation are pyranometers. There are two main types of pyranometers, thermopile pyranometers and photo-diode based pyranometers. Thermopile pyranometers are based on the thermoelectric effect, the generation of voltage from temperature differences in two dissimilar metals, while the photo-diode based pyranometers are based on the photoelectric effect as the emission of electrons by a surface, typically a metal, in response to the absorption of photons (i.e., individual quanta of light).

The electrical signal generated by pyranometers is proportional to the incident short-wave radiation. It results that incident short-wave irradiance $(E)$ is directly calculated as (in the case of a thermopile pyranometer):

$$
E=V_{t p} / S,
$$

where: $V_{t p}$ is the measured thermopile output voltage and $S$ is the sensitivity of the pyranometer, typically in the order of $10 \mu \mathrm{V} / \mathrm{Wm}^{-2}$. 
Various properties of pyranometers are of concern when evaluating the uncertainty and quality of radiation measurements: (a) resolution, as the smallest detectable change; (b) stability, as the resistance to response degradation that occurs mainly as a consequence of exposure to ultraviolet radiation that change the absorptivity of the receiver over time, leading to a decrease in sensor sensitivity typically between 0.5 and $1.0 \%$ per year; (c) non-linearity, which is the deviation of the sensor sensitivity as the irradiance level increase or decrease; (d) the dependence of the sensor sensitivity upon elevation and azimuth angle of incidence, which should ideally be a Lambert's cosine response, proportional to the cosine of the incident angle; (e) temperature response, as the change in sensitivity as instrument temperature changes; (f) thermal offset that corresponds to a subtle thermal loss mechanism that lower the detector temperature with respect to the body, resulting in a negative signal that affects thermopile pyranometers; (g) spectral response, as the deviation from a flat response over the spectrum, which is largely determined by the spectral transmission of the domes and the spectral absorption of the detector coating. These properties are discussed more in details in Vignola et al. (2012) and WMO (2008).

The International Organization for Standardization (ISO) and the World Meteorological Organization (WMO) have classified pyranometers into three classes, based on their measurement performance characteristics (Table A2).

At ICOS ecosystem stations, the following criteria must be met:

- Pyranometers used for $S W_{-} I N$ and $S W_{-} O U T$ measurements must have a $180^{\circ}$ field of view (FOV).

- Pyranometers used for $S W_{-} I N$ and $S W \_O U T$ measurements must meet the specifications required for the First Class (ISO 9060:1990 classification) or Good Quality (WMO class) pyranometers ( $c f$. Table A2). In the case that a specific requirement (e.g. non-linearity of sensor sensitivity, spectral selectivity) differs between First Class ISO and Good Quality WMO, the less demanding criteria is required for ICOS.

- At ICOS ecosystem Class 1 stations, SW IN should be redundantly measured with a dedicated individual pyranometer, in addition to the $S W_{-} I N$ measurement from the 4-components net radiometer. This individual pyranometer should ideally meet the specifications required for Secondary Standard (ISO 9060:1990 classification) or High Quality (WMO class) pyranometer, and at least the ones of First Class (ISO 9060:1990 classification) or Good Quality (WMO class) pyranometers ( $c f$. Table A2). It must be installed on a stable location (little sensitive to thermal dilatation/retraction of the structure) and in an easily reachable place allowing proper levelling and maintenance.
Incoming and outgoing long-wave radiation

(LW IN and LW_OUT)

The radiometers used to measure directly terrestrial and atmospheric long-wave radiation are called pyrgeometers. These instruments use a thermopile detector covered by a dome with an inside surface coated with an interferential filter. The short-wave cutoff frequency is generally at 3-5 $\mu \mathrm{m}$ and the long-wave cutoff at 30-50 $\mu \mathrm{m}$. The net flux of infrared radiation at the exposed junction of the thermopile is the sum of long-wave irradiance intended to be measured and others radiation terms emitted or reflected by the dome and the thermopile (Vignola et al., 2012). As a consequence, the pyrgeometer equations for calculating the incident long-wave irradiance $(L)$ are expressed as functions of measured thermopile output voltage $\left(V_{t p}\right)$ and measured temperature (i.e. the dome interference filter temperature $T_{D}$ and case/body temperature $\left.T_{B}\right)$. Depending on the instrument design and calibration procedures, the measured long-wave irradiance can be formulated in different ways (Reda et al., 2002, 2003). One of the most common is the simple form of Albrecht and Cox's formula (Albrecht and Cox, 1977):

$$
L=V_{t p} / c+\sigma T_{B}{ }^{4}-k \sigma\left(T_{D}{ }^{4}-T_{B}{ }^{4}\right),
$$

where: $c$ is the thermopile detector sensitivity, $\sigma$ is the Stephan-Boltzmann constant, and $k$ is the dome correction factor. Some pyrgeometers are designed to minimize the difference in temperature between the dome and the pyrgeometer body, which removes the last term of Eq. (8), making the measurement and calibration simpler (Vignola et al., 2012):

$$
L=V_{t p} / c+\sigma T_{B}^{4} .
$$

The properties of pyrgeometers affecting measurement uncertainty are similar to those of pyranometers (e.g. resolution, non-linearity, temperature response, thermal offsets, spectral response), but no standard classification exists yet for pyrgeometers. In absence of international standards, some minimum quality requirements for the pyrgeometers used at ICOS ecosystem stations have been defined by taking similar specifications thresholds as the ones required for First Class (ISO 9060:1990 classification) or Good Quality (WMO class) pyranometers (Table A3).

At ICOS ecosystem stations, the following criteria must be met:

- Pyrgeometers used for $L W \_I N$ and $L W \_O U T$ measurements must meet the minimum requirements summarized in Table A3.

- Pyrgeometers used for long-wave radiation measurements must present a spectral response covering the range 4.5 and $40 \mu \mathrm{m}$ and overall good quality characteristics that ensure an overall reachable uncertainty in daily totals inferior to $\pm 10 \%$. 
- Although both terrestrial and atmospheric long-wave radiation should be measured with a FOV of $180^{\circ}$, many commercial pyrgeometers currently present a FOV of $150^{\circ}$. Such $150^{\circ}$ FOV pyrgeometers are acceptable for upward long-wave radiation measurements at ICOS ecosystem stations, whereas downward long-wave radiation must be measured with $180^{\circ} \mathrm{FOV}$ pyrgeometers.

Incoming and outgoing photosynthetic photon flux density (PPFD IN, PPFD OUT and PPFD BC IN)

Photosynthetic photon flux density $(P P F D)$ is measured with PAR Quantum sensors (generally photo-diode based radiometers) using filters to accept radiation between about 400 and $700 \mathrm{~nm}$.

The performance of PAR Quantum sensors depends on the quality of its basic components (i.e. the photodiode detector, the inference filters and the cosine diffuser). In absence of an international standard classification (neither ISO nor WMO), minimum quality requirements have been defined (Table A4), based on state-of-the-art commercial sensors.

Commercially available PAR Quantum sensors are of lower quality than pyranometers. Specifications provided by manufacturers are often less precise than for pyranometers or pyrgeometers. Nevertheless, extensive inter-comparison experiments by some international research groups (often unpublished results) for different sensor models, seems to indicate that sensors built using silicon photodiodes perform better (compared to models using photodiodes made of other material) in terms of overall accuracy and stability, two specifications of critical importance for a longterm measurement network such as ICOS.

At ICOS ecosystem stations, the following criteria must be met:

- PAR Quantum sensors used for measurements of PPFD (PPFD IN, PPFD OUT and PPFD BC IN) must meet the minimum specifications requirements presented in Table A4.

- PAR Quantum sensors used for measurements of PPFD_IN and PPFD_OUT must be based on silicon photodiodes.

\section{Diffuse radiation ( $S W \quad D I F$ and $P P F D \_D I F$ )}

The typical approach to measure incoming diffuse radiation from the sky is to use an upward looking radiometer with a FOV of $180^{\circ}$ in association with shading devices to avoid that direct beam radiation from the sun reaches the sensor. Best quality measurements are obtained using an automated tracking disk, or ball, that shades the solar disk from the sensor FOV. Nevertheless, such systems are expensive and require strict maintenance.

Another option is to use a fixed shadowband or shade ring to prevent direct radiation beam to reach the sensor. Because such shadowband or shade ring can block over $20 \%$ of the diffuse irradiance (Vignola et al., 2012), a cor- rection factor is needed to account for the excluded diffuse irradiance. At the current state-of-the-art, measurements of diffuse radiation using fixed shadowbands are considered to present high uncertainties associated with the mathematical correction factor (Vignola et al., 2012). In addition, this method requires frequent manual adjustment, since the shadowband must be regularly aligned to keep the radiometer detector within $1.5^{\circ}$ of the centre of shadow cast by direct sunlight and taking into account that solar declination changes rapidly $\left(0.4^{\circ}\right.$ per day) when the sun is near the equinoxes.

An alternative method is to use measuring devices that include several miniature sensors (either thermopiles or photodiodes) and a complex shading pattern to measure the diffuse component of incident solar radiation. The complex shading pattern and miniature sensors are arranged such that the values of global and diffuse horizontal irradiance can be calculated from the individual sensor readings by an inbuilt microprocessor. The advantage of such measuring systems is that they do not include any moving parts, shade rings or motorised tracking devices, and consequently do not require routine adjustment or polar alignment.

At ICOS ecosystem stations, the following criteria must be met:

- Tracker shading disk systems with a standard radiometer and multi-sensor instruments with complex shadow pattern are both adequate to measure diffuse radiation (i.e. $S W \_D I F$ and PPFD_DIF) at ICOS ecosystem stations.

- Shadowband based systems are not accepted. Their use would lead to important uncertainty in the estimation of the ratio diffuse/global radiation by adding up uncertainty associated with shadowband correction factor to inherent uncertainty associated with estimation of this ratio from 2 different instruments (in particular because of different directional response of sensors).

- If a tracker shading disk system is used for measuring diffuse short-wave radiation $\left(S W_{-} D I F\right)$, the used pyranometer must meet the specifications required for the First Class (ISO 9060:1990 classification) or Good Quality (WMO class) pyranometers ( $c f$. Table A2).

- If a multi-sensor instrument with complex shadow pattern is used for measuring diffuse short-wave radiation $\left(S W_{-} D I F\right)$, the associated pyranometers must meet the specifications required for the Second Class (ISO 9060:1990 classification) or Moderate Quality (WMO class) pyranometers ( $c f$. Table A2). Nevertheless, it is highly recommended that the associated pyranometers meet most of the specifications required for the Secondary Standard (ISO 9060:1990 classification) or High Quality (WMO class) pyranometers, except for the directional response, for which this type of instrument present typically lower performance because of shadow patterns. 
- If a tracker shading disk system or a multi-sensor instrument with complex shadow pattern is used for measuring PPFD_DIF, the associated PAR Quantum sensor must meet the minimum specifications requirements presented in Table A4.

\section{INSTRUMENTAL SET UP}

Location and exposure of sensors measuring downward radiation quantities $\left(S W_{-} I N, L W_{-} I N, S W_{-} D I F\right.$, PPFD_IN, PPFD_DIF)

For measurements of downward radiation variables, upward looking radiometers have to be installed horizontally, ideally at a site free from obstructions, or at least has no obstruction with an angular size greater than $5^{\circ}$ in any direction, and which has a low sun angle at all times during the year.

The actual horizon of instruments may differ from the theoretical horizon because of local topography (nearby hills, mountains), buildings, trees or other instruments or objects. In some cases, other instruments or objects will create reflecting surfaces from which additional radiation will be incident on the receiver of the sensor of interest. The angular position (elevation, azimuth) of all prominent features within the field of view of the instruments should be properly catalogued.

At ICOS ecosystem stations, the following criteria must be met:

- Upward looking radiometers must be horizontally mounted.

- The actual horizon of instruments should be free from infrastructure related obstructions (only unavoidable obstructions due to local topography are not considered here). As minimum requirement, infrastructure related obstructions presenting an angular size greater than $5^{\circ}$ for the FOV of upward looking radiometers must be avoided.

- Infrastructure related obstructions, such as other instruments, mounting device, boxes, tower/mast structure, etc., must not cast any shadow on the radiometer sensors at any time of the year.

- When installed on a mast or a tower, the radiometers should be mounted south of the mast/tower (for stations in the northern hemisphere, opposite for southern). If conflicting with the eddy covariance (EC) system a compromise has to be found following Rebmann et al. (2018).

- Care must be taken such that instruments do not interfere with each other. Ideally, instruments should be far enough apart that they become insignificant objects in the FOV of adjacent instruments. Space limitations, however, often restrict the instruments separation, in particular at sites with relatively tall canopies where only a single structure (mast/tower) is available to install sensors above canopy level. In that case, the radiation instruments must be lined up in a poleward direction with slightly increasing elevation to reduce such interferences (i.e. for stations in northern hemisphere, the different radiation sensors should be lined from South to North with slightly increasing elevation).

- A mapping of the actual horizon of the instruments by any convenient mean (e.g. compass and clinometer, hemispherical fisheye photography) must be performed by cataloguing the elevation angle of all obstructing features at $10^{\circ}$ intervals beginning at $0^{\circ} \mathrm{N}$ and ending at $350^{\circ}$. If objects are in the near FOV, separate surveys must be made from the location of each instrument if they are affected differently. Such surveys are typical in surface radiation measurement networks (WMO, 2005) and must be carried out when a new radiation instrument is installed. If significant changes in the horizon occur, they must be immediately documented, and the mapping of horizon updated accordingly.

Location and exposure of sensors measuring upward radiation quantities $\left.S W \_O U T, L W \_O U T, P P F D \_O U T\right)$

For measurements of upward radiation variables, downward looking radiometers should be installed horizontally and their FOV should ideally be entirely and exclusively the targeted surface. In practice, however, the tower structure, mounting devices or other objects are within the FOV of the instrument. The set up should ensure minimal disturbance of the downward looking instruments FOV, in order that obstructing elements cause less than a $2 \%$ error in the measurement, as recommended by WMO (2008). For practical limitations and constraints at eddy covariance sites, such strict threshold of $2 \%$ will be used as a target but not as a compulsory requirement.

The tower from which the instruments are mounted should be as compact and transparent as possible but sturdy enough for individuals to climb it to service the instruments. Open towers provide less interference of the radiation flux than solid towers of the same dimension. The further away the instruments are mounted from the tower using booms, the less the tower influence is on radiation field. In case of a radiometer located at a distance $\mathrm{d}$ from a solid tower of diameter $\mathrm{D}$, the fraction of radiation intercepted is approximately $\mathrm{D} /(2 \pi \mathrm{d})$.

At ICOS ecosystem stations, the following criteria must be met:

- Downward looking radiometers must be horizontally mounted.

- When installed on a mast or a tower, the radiometers should be located and oriented such as the impact of the instrumentation (radiometers, mounting device, tower, other devices...) on the observed surface is minimized. In the northern hemisphere, this implies that the downward looking radiometers must be mounted on the southern side of the mast/tower.

- In order to limit the interference of the supporting structure (mast/ tower) on upward radiation measurements, the structure elements should never cover more than $10 \%$ 
of the sensor FOV. When installed using a boom from a mast/tower, assuming a vertical structure (mast or tower), this implies that the sensors must be located at a minimum horizontal distance of $1.6 \mathrm{D}$ from the structure ( $\mathrm{D}$ being the diameter, or apparent width of the vertical structure).

\section{Mounting of instruments}

It is crucial that the mounting design, which includes manufacturer specific supports or mounting brackets, ensures both stability and allows precise levelling of the instrument. The stand, boom or platform should be rigid enough to avoid that the horizontal position of the sensor is changed, especially during periods of high wind.

At ICOS ecosystem stations, the following criteria must be met:

- When mounted using a boom from a tower/mast, the radiation sensors must be installed on a dedicated boom with no other instrumentation, to avoid the risk of small changes in position due to maintenance or installation of other instruments. Nevertheless, various radiation sensors can be installed on a single boom.

- Instruments must be easily accessible for regular maintenance. If the sensors are difficult to access for the support personnel, the quality of maintenance will be reduced, and the quality of the measurements could hence be significantly affected. Access to the downward looking pyranometer and pyrgeometer for levelling and cleaning must be possible without disturbing significantly the observed surface beneath.

Ventilation and heating of instruments

Ventilators are extremely useful for keeping the domes of pyranometers free of moisture and dust, preventing dew and frost formation, and reducing measurement errors associated with the effect of variable wind intensity on the radiative balance of the domes. They are considered as a necessary addition for any pyranometer installation if obtaining a complete and accurate measurement record is important (Vignola et al., 2012). Ventilation is expected to prevent dew and frost formation in most cases, but at some sites experiencing very cold temperatures, it is likely that ventilation will not be enough to prevent frost formation or ice deposition onto the sensors. Therefore, at such sites, sensors should also be heated.

At ICOS ecosystem stations, the following criteria must be met:

- Radiometers used for short-wave and long-wave irradiance measurements (i.e. $S W_{-} I N, S W_{-} O U T, L W_{-} I N$, $\left.L W \_O U T\right)$ must be permanently ventilated. They should be also heated at cold sites when necessary to prevent frost formation.

\section{Signal routing and data loggers}

The routing of the signal cables from the instruments to the data acquisition system should be done with care. As most surface-based radiometers are thermopile instruments, the maximum signal is usually about $10 \mathrm{mV}$ for an irradiance of $1000 \mathrm{~W} \mathrm{~m}^{-2}$. Such low-voltage signals can be affected by large line resistance, due to long cable lengths, and electrical interference from other sources, specifically AC power lines running parallel to the signal lines. Shielded twisted pair cable should be used for low-voltage signals and should be connected as differential measurement at the data logger. The shield should be connected to the ground at one end and left unattached at the other end to prevent ground loops. Signal cables should also be physically isolated from power cables, and if they have to cross each other they should cross at a right angle to minimize induced signal.

The data logger should be selected according to several criteria, some of them being independent of radiation measurements. Some characteristics are of special relevance for radiation measurements and therefore should be considered. First, the accuracy and the linearity of the data logger should be better than the one of sensors used. Data loggers with a $0.5 \%$ accuracy or better are needed to avoid additional measurement uncertainty to the data. Also, the resolution of the data logger, that should be able to measure with $\mu \mathrm{V}$ resolution, should not alter the quality of the radiometer's outputs. Finally, the clock of the data logger should have minimal drift. Since time stamp accuracy is essential for data quality control routines of radiation measurements, discrepancy between data logger time and true reference time (i.e. UTC) should be maintained very low, typically less than a few seconds.

At ICOS ecosystem stations, the following criteria must be met:

- All radiometers used must use shielded cables for analogue signal transmission and must be connected as differential measurement at the data logger or use digital output when available.

- In addition, it is recommended to follow suggestions about signal cable routing as described in Vignola et al. (2012) and the operation manual of the Baseline Surface Radiation Network (McArthur, 2005).

- All data loggers used to log radiometers raw outputs must have a resolution $<1 \mu \mathrm{V}$ and an accuracy $<0.5 \%$ for measurements of analogue signals.

- The clock of data loggers used to log raw radiometers outputs should be maintained within $\pm 1 \mathrm{~s}$ of true reference time, and the discrepancy with true reference time must never be larger than $10 \mathrm{~s}$. 


\section{SPATIAL AND TEMPORAL SAMPLING DESIGN}

Sampling frequency and measurement interval

- The sampling frequency is the frequency at which samples are taken. A sample is a single measurement, typically one of a series of instantaneous readings of a sensor system.

- The measurement interval or observation period is the length of time over which one observation is made and stored, during which a number of individual samples are taken and averaged. An observation is the result of the sampling process, being the quantity reported or recorded.

The practical recommended scheme for determining sampling frequency of meteorological variables, as adopted by the Commission for Instruments and Methods of Observation at its tenth session (CIMO-X, 1989), is as follows:

- Samples taken to compute averages should be obtained at equi-spaced time intervals which:

(i) Do not exceed the time-constant of the sensor; or

(ii) Do not exceed the time-constant of an analogue low-pass filter following the linearized output of a fastresponse sensor; or

(iii) Are sufficient in number to ensure that the uncertainty of the average of the samples is reduced to an acceptable level, for example, smaller than the required accuracy of the average.

Criteria (i) and (ii) are the ones used for determining sampling frequency of automatic sampling systems, whereas the criterion (iii) is generally applicable to low sampling frequency such as in manual observations. Criteria (i) and (ii) derive from the Nyquist frequency. If the sample spacing $t \leq T_{I}$ ( $T_{I}$ is the response time of instrument system) then the sampling frequency $n \geq 1 / T_{I}$, prevents aliasing. In the case of radiation measurements, the Baseline Surface Radiation Network (BSRN) recommends a sampling frequency of $1 \mathrm{~Hz}$ (McArthur, 2005). This specification is based upon the typical 1/e response time of first class pyranometers being approximately one second. The sampling frequency and measurement intervals used in the major surface radiation observation networks are as follows:

- The Solar Infrared Radiation Station (SIRS) of the National Renewable Energy Laboratory sample radiometers outputs at $0.5 \mathrm{~Hz}(2 \mathrm{~s}$ interval) and record 1 -minute average, minimum, maximum and standard deviation (SIRS Handbook, Stoffel, 2005).

- The stations of the Surface Radiation budget network (SURFRAD) supported by the National Oceanic and Atmospheric Administration, sample radiometers outputs at $1 \mathrm{~Hz}$ and record 3-min mean and standard deviation (Augustine et al., 2000).

- The Baseline Surface Radiation Network stations sample radiometers outputs at $1 \mathrm{~Hz}$ and record 1 -min mean, minimum, maximum and standard deviation (McArthur, 2005).
At ICOS ecosystem stations, the following criteria must be met:

- Sampling frequency for all radiation instruments raw outputs must ideally be $1 \mathrm{~Hz}$. Nevertheless, if such $1 \mathrm{~Hz}$ sampling rate results too challenging for the overall data logging capacity available at a site station, the sampling rate may be decreased down to $0.05 \mathrm{~Hz}$.

- The measurement interval period must be 1 min or lower. Data should be recorded and archived into the final database at this measurement interval resolution.

Spatial sampling representativeness

Representativeness of upward irradiances and below canopy PPFD measurements is linked to their spatial sampling design.

Sensors measuring upward radiation quantities (SW_OUT, LW_OUT, PPFD_OUT)

To measure the upward radiation quantities, it is necessary to place the downward looking sensors at a suitable distance above the ground, both to limit shading effect of the instrumentation on the surface and to obtain a sufficient spatial averaging of the measurements to ensure representativeness for the ecosystem considered. WMO (2008) indicates that a height of $2 \mathrm{~m}$ above short homogeneous vegetation, such as a short grass cover, is usually adopted for net radiation measurements, while in the case of tall vegetation, such as a forest, the height should be sufficient to average over local surface small scale heterogeneities. The BSRN, which operates surface radiation observations with the highest quality standard, states that downward looking sensors should only be installed when the sensor can be located at a minimum height of $30 \mathrm{~m}$ above the surface to increase the representativeness of its FOV (McArthur, 2005).

Because of specific observational objectives of ICOS stations, it is most important that the measurements are sufficiently representative of the entire ecosystem that is studied, in particular of the footprint area of the EC flux measurements. While $2 \mathrm{~m}$ above canopy can be an adequate height requirement for short and homogeneous vegetation covers such as in meadows and croplands, it is insufficient to ensure a proper spatial representativeness in all cases, in particular for tall vegetation or for ecosystems with heterogeneous patchy surface such as open shrublands. As a consequence, the minimum height of measurements required to eliminate local heterogeneity and ensure proper representativeness is site specific and depends on vegetation cover characteristics. For short canopies presenting high horizontal heterogeneity, a dedicated structure (typically a mast) higher than the structure used for the EC system may be necessary to ensure a proper representativeness of the footprint of the EC flux measurements. At all short canopy stations, it is recommended to have a dedicated mast for upward radiation measurements separated 


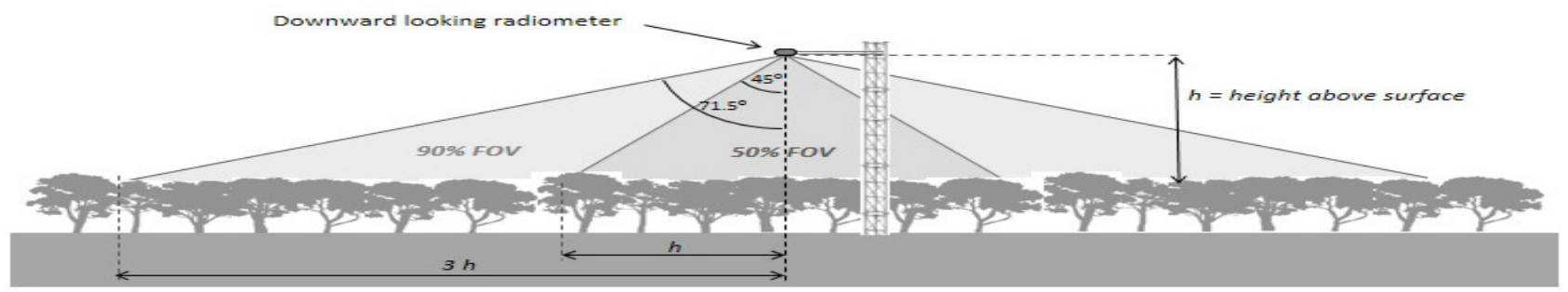

Fig. 1. Representation of limits of the areas corresponding to the field of view (FOV) contributing to 50 and $90 \%$ of total signal for a downward looking radiometer with $180^{\circ} \mathrm{FOV}$ and cosine response.

from the EC system structure, in order to guarantee that the sensor FOV corresponds mostly to non-disturbed targeted ecosystem, free from bulky material and/or disturbances due to maintenance and service of the main EC tower.

For downward looking radiometers installed at a height of $h$ metres above the observed surface (Fig. 1), 50\% of the measured irradiance originates from a circular surface underneath having a radius of $h$, (this figure is $90 \%$ for a radius of $3 h$ ), assuming that the sensor has a FOV of $180^{\circ}$ and a perfect cosine response. The surface area contributing to $90 \%$ of the measurement is hereafter named the main FOV of downward looking radiometers and the area contributing to $50 \%$ is named the central FOV.

At ICOS ecosystem stations, the following criteria must be met:

- Downward looking radiometers should be installed at the maximum height that is practically possible from the supporting structure (mast/tower) at the site, in order to increase the representativeness of their FOV. In all cases, they must be located at a minimum height of $2 \mathrm{~m}$ above the canopy in low vegetation ecosystems (i.e. grasslands, crops, mires) and a minimum height of $5 \mathrm{~m}$ above the canopy in tall vegetation ecosystems (i.e. forests, orchards).

- The central FOV that contribute to $50 \%$ of measured signal should consist mostly of non-disturbed ecosystem and be representative of the targeted ecosystem. It must be free of large specular reflective objects, such as plane metal surfaces, and not significantly impacted by station maintenance or operation.

- A proper description of the surface within the main FOV must be made by any convenient mean (e.g. hemispherical fisheye photography) after the installation of instruments and properly documented and archived as metadata information. When significant changes in the main field of view occur, they should be properly documented, with exception of "natural" changes at whole ecosystem scale, such as changes related to vegetation phenology or meteorological events (blow-down, downburst).

- Changes in location of downward looking radiometers should be avoided as much as possible during the life time of the station. If a measurement location of an upward radiation variable is significantly changed, for example performed from a different tower/mast, the measurement should be performed in parallel at both locations over at least a full year to assess the impact of the change of location onto the long-term time series of the measurements.

Sensors measuring below-canopy $P P F D$

(PPFD BC IN)

Below canopy irradiance in terrestrial ecosystems are often associated with significant spatial heterogeneity. Therefore, monitoring of below-canopy PPFD (PPFD $\left.B C_{-} I N\right)$ that allows a robust estimation of the mean $P P F D \_B C \_I N$ for a given ecosystem, requires using a mobile automated systems (such as tram-systems) that allow a representative spatial sampling of PPFD_BC_IN with a limited number of sensors, or a rather large number of sensors spatially distributed at fixed-locations. Due to the cost and inherent problems of maintenance of mobile automated systems for long-term measurements, we discard their systematic use at ICOS terrestrial ecosystem stations. Therefore, we only consider the use of spatially distributed sensors at fixed-locations. This manuscript provides only basic guidelines and very minimal requirements for measurement of PPFD_BC_IN and should not be seen as a complete state-of-the-art protocol for $P P F D_{-} I N \_B C$ measurements.

The number of fixed-location individual PAR Quantum sensors required to measure the mean and standard deviation of true ecosystem $P P F D \_B C \_I N$ with a given accuracy is site-specific, since it is related to the spatial variability of PPFD_BC_IN which largely depends on ecosystem vegetation canopy. For the sake of simplicity and based on previous experience within carbon flux tower networks, this manuscript defines only the minimum number of sensors that should be used for measuring PPFD_IN_BC at ICOS ecosystem stations.

Many methods can be applied to design point-based sampling strategy. Due to high site variability in terrestrial ecosystem vegetation characteristics and operational constraints (either practical constraints, technical constraints for sensors signal routing, constraints associated with other instrumentation or sampling, etc.), this manuscript does not provide any mandatory method or guidelines for designing the spatial sampling scheme, and the choice of spatial location of the individual photosynthetically active radiation $(P A R)$ Quantum sensors is left to the ICOS station PIs. 
At ICOS ecosystem stations, the following criteria must be met:

- PPFD_BC_IN must be measured with a minimum of 15 individual PAR Quantum sensors.

- The PPFD_BC_IN sensors must be horizontally mounted.

- All PPFD_BC_IN sensors must be located at the same height above the ground. This height is typically $10-50 \mathrm{~cm}$ but can vary depending on vegetation structure at the different sites but must be low enough in order to ensure that more than $95 \%$ of the photosynthetically active organs of the overall ecosystem vegetation is located above the sensor level at any time of year (including understorey vegetation at forest sites but excluding ground cover plants such as mosses).

- The spatial distribution of $P P F D_{-} B C_{-} I N$ sensors is to be decided by ICOS station PIs.

- The average distance between close-by sensors must not be less than $25 \%$ of the canopy height to ensure a minimum spatial extension of the overall sampling.

- The design of the horizontal spatial location should avoid that the FOV of PPFD_BC_IN sensors is affected by maintenance activities or by ancillary data collection activities (such as biomass or soil sampling, etc.).

- The mounting structure of PPFD_BC_IN sensors must not influence significantly the growth or development of vegetation.

- The spatial location of each individual PPFD BC IN sensor must be reported as metadata information with the highest precision possible (minimum $10 \mathrm{~cm}$ precision for height and $50 \mathrm{~cm}$ for horizontal location).

Assessment of spatial representativeness of continuous PPFD_BC_IN measurements

The spatial sampling design of the $P P F D_{-} B C_{-} I N$ measurements may be not adequate to capture the mean "true" ecosystem PPFD_BC_IN with sufficient accuracy at some sites. Therefore, the representativeness of the continuous $P P F D \_B C \_I N$ measurements should be assessed by performing complementary discrete $P P F D_{-} B C_{-} I N$ measurements with higher spatial coverage on campaign mode.

At ICOS ecosystem stations, the following criteria must be met:

Complementary discrete PPFD_BC_IN measurements should be performed on campaign mode following some basic requirements:

- These discrete measurements campaigns should be performed at least at two different periods of the year, which should be selected in order to cover the extreme of seasonal variation in vegetation characteristics, in particular seasonal variation in leaf area index (LAI). One measurements campaign should be performed when LAI is close to its annual maximum, and the second campaign when LAI is close to its annual minimum. For sites presenting seasonal minimum of LAI close to zero, such as some croplands or deciduous forest, the second campaign should be performed when LAI is expected to be between 25 and $50 \%$ of its annual maximum value.

- The measurements must be made using a portable $P A R$ Quantum sensor meeting the minimum specifications requirements presented in Table A4.

- The measurements must be performed within central hours of the day (local solar noon $\pm 2 \mathrm{~h}$ ) on a single day with clear sky conditions.

- The measurements should be performed at the same height $( \pm 10 \mathrm{~cm})$ as the installation height of the continuous PPFD_BC_IN sensors.

- The spatial sampling scheme is defined by the station PIs but must include a minimum of 100 point measurements and cover the area contributing to $80 \%$ of daytime eddy covariance fluxes, as estimated from a long-term footprint climatology.

- The individual measurements values of PPFD_BC_IN along with timestamp and spatial location must be stored for each sampling point, with same precision as for the continuous measurement sensors.

The PPFD_BC_IN estimates obtained from these discrete measurement campaigns should be compared with continuous PPFD_BC_IN measurements. If the discrepancy between mean $P P F D_{-} B C_{-} I N$ values is greater than $5 \%$, the spatial sampling scheme of continuous $P P F D_{-} B C_{-} I N$ sensors should be modified, either by changing their spatial locations or by increasing the number of sensors.

Measurement of soil surface albedo in the PAR domain

One major potential application of PPFD_BC_IN measurements consist in allowing estimation of the A bsorbed Photosynthetically Active Radiation (APAR) and the Fraction of Absorbed Photosynthetically Active Radiation (FAPAR), the latter being one of the Essential Climate Variables recognized by the UN Global Climate Observing System (GCOS). FAPAR is a critical variable for most of models used to perform large scale estimates of carbon uptake from remote sensing products, and more generally in both vegetation biomass production and plant growth modelling.

FAPAR can be calculated as:

$$
F A P A R=\frac{P P F D_{-} I N-P P F D_{-} O U T-P P F D_{-} B C_{-} I N+P P F D_{-} B C_{-} O U T}{P P F D_{-} I N},
$$

where PPFD_BC_OUT is outgoing below canopy PPFD, i.e. upward $P P F D$ reflected by the soil.

At sites measuring $P P F D_{-} B C_{-} I N, P P F D \_B C \_O U T$ is the missing quantity to estimate FAPAR from in situ measurements. Nevertheless, performing continuous measurements of PPFD_BC_OUT implies important costs and practical complications for a variable that is not strictly necessary, as FAPAR can be calculated as: 


$$
F A P A R=\frac{P P F D_{-} I N-P P F D_{-} O U T-P P F D_{-} B C_{-} I N\left(1-a_{\text {Soil }}\right)}{P P F D_{-} I N},
$$

where $a_{\text {soil }}$ is the soil albedo in the PAR domain. $a_{\text {soil }}$ may present important spatial and temporal variations for a given ecosystem. The main factors affecting temporal variations are water content of top soil, as well as seasonal variations in litter layer composition. Nevertheless, for most ecosystems, such temporal variations have less influence on the overall uncertainty associated to FAPAR estimates as calculated from Eq. (11). For FAPAR calculation, $a_{\text {soil }}$ may be treated as a site-specific average value, constant (in time), which can be estimated from soil albedo measurement campaigns.

At ICOS ecosystem stations, the following criteria must be met:

- A site specific value of the average soil albedo should be determined by performing at least one soil albedo measurement campaign.

- The soil albedo measurements must be made using a portable sensor able to measure at the same time both downward PPFD and upward PPFD and meeting the minimum specifications requirements presented in Table A4.

- The soil albedo measurements must be performed within central hours of the day (local solar noon $\pm 2 \mathrm{~h}$ ) on a single day.

- The soil albedo measurements must be performed at the same height $( \pm 10 \mathrm{~cm})$ as the installation height of the continuous PPFD_BC_IN sensors.

- The spatial sampling scheme of soil albedo campaign is defined by the station PIs but must include a minimum of 100 point measurements and cover the area contributing to $80 \%$ of daytime eddy covariance fluxes, as estimated from a long-term footprint climatology.

- The individual measurements values of $a_{\text {soil }}$ along with spatial location with precision of $1 \mathrm{~m}$ should be stored for each sampling point.

\section{CALIBRATION AND MAINTENANCE}

\section{Calibration of instruments}

An absolute measurement standard is required to assess the absolute accuracy of a pyranometer or a pyrgeometer. Therefore, a critical aspect of the calibration of pyranometers and pyrgeometers is its traceability to a recognized international standard.

Proper calibration of pyranometers can be performed in different standardized manners (ISO 9847:1992; ISO 9846:1993) but should always be traceable to the World Radiometric Reference (WRR). The WRR, which constitutes the internationally recognized measurement standard for solar irradiance (Fröhlisch, 1991), is determined by a group of self-calibrated absolute cavity radiometers named the World Standard Group (WSG) maintained at the World Radiation Center (WRC) in Davos, Switzerland. The cali- bration of commercially available Secondary Standard pyranometers and of some First class pyranometers is traceable to the WRR.

Another important consideration is to calibrate a radiometric instrument in the same environment it will be used for routine measurements, the estimated measurement uncertainties being generally more applicable (Vignola et al., 2012). In-situ calibration can be also made following different calibration procedures, but always require the comparison with a reference instrument traceable to WRR.

At ICOS ecosystem stations, the following criteria must be met:

- Factory calibration of all the radiation sensors should be performed regularly following manufacturer recommendations, typically once every two years. The factory must provide calibration certificate and new calibration coefficients.

- Factory calibration of the pyranometers and pyrgeometers must be performed following standard methodology (ISO 9847:1992; ISO 9846:1993). For pyranometers, calibrations must be traceable to WRR international standard.

- In case no spare instruments are available to ensure the continuity of the radiation measurements during factory calibration services, the calibration should be made outside of the growing season (or season with lowest carbon fluxes) when possible and its duration should be minimized. The calibration schedule must be organized to ensure that at any moment, at least one incoming global radiation sensor (either $S W_{-} I N$ or PPFD_IN) is in operation at the station.

\section{Maintenance}

Routine preventive maintenance schedules require a continuous effort but constitute the best way to maintain a measuring system close to its nominal performance, allowing the final measurements quality to be close to the «intrinsic» performances of the used sensor. This statement is particularly true for in situ radiation measurements, since particular care must be taken with routine maintenance of the radiometers to achieve a high standard for the quality of the measurements. Ideally such routine maintenance should be performed daily, as required in high-quality standard networks such as the BSRN (McArthur, 2005).

High-quality radiation measurements require minimal maintenance other than cleaning the dome or sensor surface on a regular basis and making sure the desiccant does not become saturated with moisture. It should be months to a year between desiccant changes for a properly assembled instrument, and the need of more frequent changes is usually an indication that a seal has developed a leak (Vignola et al., 2012). To clean the instrument domes or windows, distilled water is the preferred cleaning agent. Ethanol may be used in icing conditions but should be avoided if maximum daily temperature allows using distilled water. The maintenance of radiometric instrumentation consists mainly in 
performing routine maintenance involving only cleaning the domes and diffuser disks, and a cursory inspection of the instruments.

At ICOS ecosystem stations, the following criteria must be met:

- A routine maintenance must be performed as frequently as possible, ideally daily but at least bi-weekly, and consists in checking:

(a) the levelling of sensors;

(b) that sensors are kept clean and free from dust, dew, frost, snow and rain;

(c) that domes do not retain water (any internal condensation should be dried up);

(d) That black receiver surface does not present any visual sign of degradation.

- Cleaning of the instrument domes and windows should be performed at least bi-weekly.

- The change of desiccant of radiometers or filters (for ventilation units) should be made according to manufacturer indications. The check of desiccant and filters state should be made initially at least every 3 months and can be made only every 6 months after one year of operation if a 6-month frequency is obviously enough.

- The wiring (both cables and connections) must be checked at least annually in order to assess cables or connections deterioration due to exposure to environmental conditions or damage caused by wildlife.

- Both periodic checks and all maintenance actions performed (e.g. cleaning, levelling, desiccant change, etc.) that may affect the radiation measurements, must be properly documented and reported as critical metadata information.

\section{OTHERS OPERATIONAL CONSIDERATIONS}

\section{Calculations}

When a radiation quantity requires more than one signal to be measured, such as the long-wave irradiance ( $L W_{-} I N$, $\left.L W_{-} O U T\right)$ for which at least 2 raw measurements are required, difficulties arise in providing a single true sample standard deviation for the observations averaged over the measurement interval. There are two methods of data handling that provide the exact values for both averages and standard deviation of the irradiance:

(1) Observations of each of the required signals are stored at the sampling rate $($ e.g. $1 \mathrm{~Hz})$, and the statistics of infrared irradiance can be properly calculated later on.

(2) With the increasing computation power of data acquisition equipment, the calculation of the infrared irradiance can be made in real-time by the data acquisition system. This method requires the embedding of the thermopile sensitivity and all calibration coefficients into the data acquisition system. Since this method implies a risk of error in irradiance calculation, the mean and standard deviation of each of the raw signals should be stored along with calculated infrared irradiances in order to allow postcorrections by maintaining the capability of calculating irradiance values.

At ICOS ecosystem stations, the following criteria must be met:

- For long-wave irradiance measurements ( $L W_{-} I N$ and LW_OUT), the irradiance must be calculated at sampling rate by the data acquisition system. The data that should be recorded and archived into the database are the mean and standard deviation of both raw signals (i.e. thermopile output and pyrgeometer body temperature) and long-wave irradiances.

\section{Changes in instrumentation}

In the context of long-term observations such as planned at ICOS terrestrial ecosystem stations ( $>20$ years of operation), it is critical to minimize the effects associated with changes of instrument and/or changes in the siting of specific instruments. Although the static characteristics of new instruments might be well understood, operational deployment can introduce significant discontinuity in radiation measurements such as biases. At ICOS stations, both the repeatability and the reproducibility of radiation measurements are key aspects to ensure that long-term radiation measurements are consistent enough, allowing to detect and analyse the response of ecosystem biogeochemical cycles to long-term trends or climatic variability in radiation.

At ICOS ecosystem stations, the following criteria must be met:

- In order to assess the effect of changes in radiometric instrumentation (i.e. change of type/model of instrument), observations from new radiometers must be compared over an extended interval, of at least two months, and ideally one year, as recommended by the Guide to Climatological Practices (WMO, 1983) before the old radiometer is taken out of service. This requirement does not apply for $P P F D_{-}$ $B C \_I N$ sensors.

\section{Data acquisition of environmental variables}

Since variables such as barometric pressure, ambient temperature, relative humidity, wind speed and wind direction affect radiation measurements by influencing the energy balance of the radiation instruments, providing these data at the same frequency as the radiation data is important. Stations are encouraged to access these observations coincidentally with the radiation measurements using the same measurement interval (i.e. 1-min averages stored) to help understanding the energy balance of the radiation instruments and therefore improving the quality assessment of radiation data and the estimation of associated uncertainties. Ambient air temperature is the most crucial environmental variable in terms of impact on radiation measurements (Mc Arthur, 2005).

At ICOS ecosystem stations, the following criteria must be met: 
- Ambient air temperature data should be recorded in synchronization with the same measurement interval as the radiation data.

\section{Protection against birds}

The negative influence of birds (bird excrements and birds standing on instruments) on the quality of radiation measurements can be, at some sites, much stronger than the negative impact of bird protection devices. The decision of installing protection devices depends to a large degree on the potential of birds impacting measurements. The choice of the protection device type should be site-specific and should be both efficient and not interfere significantly with the measurement. The description of the protection devices should be part of metadata information, and they must be included in the mapping of the horizon / FOV of the instruments.

\section{FINAL DATASET AND METADATA INFORMATION}

Information to be stored as continuous dataset should include the average and standard deviation of all radiometers raw measurements outputs at measurement interval frequency (typically the thermopile or photodiode output voltages and temperature measurements from body and/or dome), but also the calculated irradiances for long wave variables ( $\left.L W \_I N, L W \_O U T\right)$, and the status $(\mathrm{I} / \mathrm{O})$ of heating and ventilation devices associated with radiometers. In the case the measurements are stored at the sampling frequency (measurement interval frequency $=$ sampling frequency), single values are stored and neither average nor standard deviation are calculated at the measurement interval frequency.

In addition, metadata information about the circumstances of radiation measurements should include type and traceability of the instrument, its calibration history, its spatial exposure and maintenance record (e.g. cleaning, levelling, desiccant replacement...). Both maintenance and calibration related information, as information regarding any aspect that affects radiation measurements, must be properly documented using a standardized format.

Metadata to be documented for each radiation variable should include:

- Radiometer characterization type, model and serial number

- Calibration factors and calibration equations along with date of calibrations.

- Mapping of the actual horizon for the radiometers measuring above canopy downward radiation quantities ( $\left.S W_{-} I N, L W \_I N, S W \_D I F, P P F D \_I N, P P F D \_D I F\right)$

- Characterization of FOV of radiometers measuring upward radiation quantities (SW_OUT, LW_OUT, PPFD_OUT)

- Any maintenance action (e.g. cleaning, levelling, desiccant change, filter change, repair, etc.) or change in set up (e.g. change in location, orientation, connections, wir- ing, data logging configuration, etc.) that may affect the radiation measurements, must be properly documented and reported as critical metadata information with time and date.

\section{RESULTS AND DISCUSSION}

\section{Usefulness of measured radiation variables}

The methodology presented in this paper covers the measurement of various radiation quantities at ecosystem scale. While incoming global solar radiation $\left(S W_{-} I N\right)$ is the most fundamental of these variables for interpreting ecosystem-atmosphere fluxes of carbon, water and energy, measuring simultaneously the full set of radiation variables presented here largely increases the usefulness and potential of the radiation measurements dataset at ICOS ecosystem stations.

Radiation variables are crucial input parameters for a broad range of Soil Vegetation Atmosphere Transfer (SVAT) models that make use of water and carbon flux measurements as key information for model calibration or validation, such as biogeochemical terrestrial ecosystem models used to assess the current land carbon balance (Sitch et al., 2008). As such, they constitute an essential complement to in situ water and carbon flux observations.

The measurement of diffuse radiation is fundamental since several studies demonstrated that diffuse radiation is being more effectively used by plant canopies for photosynthesis (Roderick et al., 2001; Gu et al., 2002; Ibrom et al., 2006; Knohl and Baldocchi, 2008), thereby increasing the $\mathrm{CO}_{2}$ sink of terrestrial ecosystems (Gu et al., 2003; Farquhar and Roderick 2003, Mercado et al., 2009). The fraction of diffuse radiation depends on sun position, cloud cover and atmospheric aerosol loadings, presenting important spatial and temporal variations. Measurements of the diffuse component of solar radiation are necessary for understanding the overall effect of radiation on ecosystem plant productivity and are also used by some Radiative Transfer Models (RTM) that simulate separately the penetration of direct and diffuse light into the vegetation canopy.

Simultaneous measurements of incoming and outgoing solar radiation allow to determine the surface albedo (the fraction of the incident radiation reflected from a surface), which is influenced by ecosystem vegetation and soil characteristics. As such, the albedo is not only important to understand the temporal patterns of net radiation but is also useful to detect seasonal or long-term changes in the ecosystem spectral characteristics, that can be associated to changes in vegetation phenology or in long term changes in vegetation characteristics (composition, structure, coverage).

Below canopy PAR measurements not only allow to obtain in situ FAPAR estimates that are useful for remote sensing products assessment, but are also very effective 
to accurately describe the seasonal and inter annual LAI dynamics in deciduous forest stands (e.g. Pilegaard et al., 2011).

At EC measurement stations, the net radiation measurements are also often used for independent assessment of the quality of EC measurements by analysing the energy balance closure in order to detect possible biases in measurements of latent and sensible heat fluxes by the eddy covariance technique (Wilson et al., 2002; Foken 2008b; Stoy et al., 2013; Perez-Priego et al., 2017).

Finally, radiation measurements are of specific relevance at ICOS ecosystem stations as an essential input parameter to properly apply gap filling procedures of net carbon ecosystem exchange (NEE) time series (Papale et al., 2006; Moffat et al., 2007). Such gap-filled NEE datasets are necessary to estimate the long-term (e.g. annual) ecosystem carbon balance. Radiation measurements are also essential parameters to apply algorithms for the partitioning of NEE between gross primary production and total ecosystem respiration (Lasslop et al., 2010).

In the specific context of ICOS ecosystem stations, radiation measurements are secondary measurements that are primarily performed to support the analysis and interpretation of the trace gas flux measurements, which are the principal object of observation. Nevertheless, for the reasons expressed above, radiation variables are very important for overall ICOS observational strategy, and therefore require high-quality measurement standard to ensure they are estimated with sufficient precision and accuracy.

\section{Rationale of methodology and instrument selection for radiation measurements}

For short-wave and long-wave radiation variables, both the methodology and the instrumentation quality criteria are based on available existing state-of-the art standards (WMO, ISO).

For measurements of net radiation, existing studies show that the four-component systems were the best in term of accuracy, followed by the two-component systems and then the all-wave net radiometers (Brotzge and Duchon, 2000; Blonquist et al., 2009). Therefore, the standard method for determining net radiation values at ICOS ecosystem stations consists in calculating the algebraic sum of the short-wave and long-wave irradiance measurements (Eq. (6)) performed by individual pyranometers and pyrgeometers. All-wave radiometers (i.e. pyrradiometers) are not considered adequate for performing net radiation measurements at ICOS ecosystem stations and therefore are not discussed in this protocol.

The redundant measurement of $S W_{-} I N$ using a dedicated single pyranometer is highly recommended to improve the overall accuracy of both $S W$ IN and NETRAD estimates. Measurement redundancy significantly reduces uncertainty associated with imperfect levelling, which can be a major source of error when $S W_{-} I N$ is measured only using a 4-components net radiometer located on a pole as it is the typical case at EC sites. It will therefore reduce the uncertainty in net radiation estimates, since $S W_{-} I N$ is both the most important component of net radiation variability and the most sensitive (in terms of error) to imperfect levelling. This also improves the final quality of $S W_{-} I N$ ICOS products by allowing better quality check procedures of $S W_{-} I N$ measurements by cross-comparison of two simultaneous $S W_{-} I N$ measurements, which is in particular very helpful to detect errors associated to dirty sensors or imperfect levelling.

\section{Uncertainties related to radiation measurements}

Uncertainty of radiation measurements includes both uncertainties associated with instrument calibration, uncertainties associated with field set-up (e.g. stability and levelling of mounting, data logger specifications, etc.), and environmental conditions that are different from that of the calibration conditions.

The Guide to Measurement Uncertainty (GUM) of the International Bureau of Weights and Measures (BIPM 1995 ) is the accepted international guide defining standard methodologies to quantify uncertainties. It is generally used for performing uncertainty analyses of highest accuracy radiation measurements (McArthur, 2005; Stoffel, 2005). The GUM defines Type A uncertainty values as derived from statistical methods, and Type B sources as evaluated by "other means," such as scientific judgment, experience, specifications, comparisons, or calibration data. Uncertainty analysis as applied to both pyranometer and pyrgeometer calibration are quite complex (Myers, 1989; Philipona et al., 1995; Reda et al., 2002, 2003, Vignola et $a l ., 2012)$ and require specific calibration procedures traceable to an international standard (Wells, 1995).

The state-of-the-art in radiation measurements currently allows high quality surface radiation measurement network to achieve uncertainty of only a few \% ( $c f$. Table A5). Nevertheless, such level of measurement uncertainty requires not only a high quality of instrumentation, but also a very careful preventive maintenance and constraining procedures of instrument calibration and inter-comparison exercises, implying important costs for long-term observational networks.

The site selection and instrumental set-up (in particular exposure) plays a critical role in determining measurement uncertainty. The overall estimated measurement uncertainty of field measurements is largely dependent upon how the instruments are installed and maintained in the field (Vignola et al., 2012). Both site selection and overall instrumental set-up at ICOS stations are influenced and constrained by measurement requirements for others variables, in particular EC flux measurements, resulting in less optimal measurement conditions compared to sites selected exclusively for radiation measurement networks. For these reasons, radiation measurements at ICOS terrestrial eco- 
system stations will often present a lower quality level than measurements performed in dedicated highest performance radiation networks such as the $B S R N$ (Ohmura et al., 1998).

A working target uncertainty of $\pm 10 \%$ for both shortwave and long-wave irradiances measurements (i.e. $S W_{-} I N$, $\left.S W_{-} O U T, L W_{-} I N, L W_{-} O U T\right)$, and $\pm 5 \%$ for short-wave incoming irradiance when a Secondary Standard pyranometer is used as dedicated single pyranometer for redundant measurement of $S W_{-} I N$, seems a reasonable objective for the ICOS ecosystem station network. Nevertheless, despite being constrained by a standard protocol, radiation measurements are likely to present a heterogeneous level of accuracy within the network depending on site-specific conditions. Coordinated actions should be taken by the ICOS terrestrial ecosystem station network in order to assess the effective level of measurement uncertainties at several stations, in particular the accuracy and stability of the measurements on the long term. This should further include operational strategies to improve the quality of radiation measurements or to correct detected degradation in the quality of the collected measurements. Reaching an uncertainty level similar to current estimated measurement uncertainties of best practices networks ( $c f$. Table A5: BSRN 2004 target, McArthur, 2005) must be the long-term objective for the ICOS network.

These uncertainty targets represent the expected accuracy related to the realisation of the measurement at a certain location. Nevertheless, despite radiation measurements being expected to be representative of the mean downward and upward irradiances for the ecosystem considered, single point measurements of radiation quantities at the earth surface are subject to both systematic and random error due to horizontal patchiness (of the surface or sky). For global radiation measurements, an analysis of measurements performed at various locations within a 2 ha area (magnitude of EC measurements) showed that bias and random error can be up to $10 \%$ and concludes that a mean stochastic and total error of approx. $5 \%$ should be assumed when relying on a single measurement that cannot be replicated adequately (Dämmgen et al., 2005). For measurements of upward irradiances, bias and random uncertainty can be much larger if the surface is highly patchy and heterogeneous.

\section{CONCLUSIONS}

1. As radiation is an essential driver of terrestrial ecosystem carbon and water flux variability, a standard methodology and minimum requirements are established to perform radiation measurement with comparable accuracy across the ICOS ecosystem stations network.

2. Instrument performance and calibration, instrument set up and routine maintenance are major factors influencing the overall accuracy of radiation measurements. Efforts should focus on ensuring that highest realistic standards are consistently met for these points at the ICOS network scale.
3. For downward looking sensors measuring radiation reflected by the surface (i.e. SW_OUT and PPFD_OUT), particular attention should be paid to select the area within the field of view of the sensors. This is particularly important since the measurements must be representative for whole ecosystem of interest. A dedicated mast/tower for radiation measurements only might be necessary.

4. Ensuring a high degree of standardization and guaranteeing a high accuracy level is too challenging for measurement of below canopy photosynthetic photon flux density at ICOS network level. As a consequence, this manuscript only provides basic guidelines and minimal requirements for performing below canopy radiation measurement at ICOS ecosystem stations.

5. Despite the establishment of a standard protocol, high heterogeneity in ecosystem characteristics and practical conditions may lead to substantial differences in radiation measurement accuracy in the long-term or across stations. Therefore, ICOS network should take coordinated actions to assess the effective level of uncertainty associated with radiation measurements at ICOS ecosystem stations.

6. ICOS provides an opportunity to detect degradation in sensors and the collected data over long time periods. Therefore it will be able to provide operational guidance to improve the overall quality of radiation measurements at network scale.

\section{ACKNOWLEDGMENTS}

A. Carrara acknowledges funding from the project DESESTRES (PROMETEOII/2014/038) and the Spanish Ministry of Economy and Competitiveness project GEISpain (CGL2014-52838-C2-2-R). L. Merbold acknowledges funding received under the Swiss National Science Foundation-funded project ICOS-CH (grant agreement: 20FI21_128992) and of ETH Zurich (0-23184-15).

Conflict of interest: The Authors declare no conflict of interest.

\section{REFERENCES}

Albrecht B. and Cox S.K., 1977. Procedures for improving pyrgeometer performance. J. Applied Meteorol., 16, 188-197.

Augustine J.A., DeLuisi J.J., and Long C.N., 2000. SURFRAD - A National Surface Radiation Budget Network for Atmospheric Research. Bulletin of the American Meteorological Soc., 81, 2341-2357.

Amesz J., 1987. Photosynthesis. Elsevier, Amsterdam.

Baker N., 1996. Photosynthesis and the Environment. Kluwer Academic, Netherlands.

Barber J., 1992. The Photosystems: Structure, Function and Molecular Biology, Elsevier, Amsterdam.

Bird R.E. and Riordan C., 1986. Simple solar spectral model for direct and diffuse irradiance on horizontal and tilted planes at the Earth's surface for cloudless atmospheres. J. Climate and Applied Meteorology, 25, 87-97. 
Blanc P., et al., 2014. Direct normal irradiance related definitions and applications: the circumsolar issue. Solar Energy, 110, 561-577. http://dx.doi.org/10.1016/j.solener.

Blonquist Jr. J.M., Tanner B.D., and Bugbee B., 2009. Evaluation of measurement accuracy and comparison of two new and three traditional net radiometers. Agric. Forest Meteorol., 149, 1709-1721.

Bonan G.B., 2008. Ecological Climatology. New York: Cambridge University Press.

Brotzge J.A. and Duchon C.E., 2000. A field comparison among a domeless net radiometer, two four-component net radiometers, and a domed net radiometer. J. Oceanic and Atmospheric Technology, 17, 1569-1582.

Dämmgen U., Grünhage L., and Schaaf S., 2005. The precision and spatial variability of some meteorological parameters needed to determine vertical fluxes of air constituents. Landbauforschung Völkenrode, 55, 29-37

Emerson R., 1958. The quantum yield of photosynthesis. Annuual Review of Plant Physiology, 9, 1-24.

Farquhar G.D. and Roderick M L., 2003. Pinatubo, diffuse light, and the carbon cycle. Science, 299, 1997-1998.

Foken T., 2008a. Micrometeorology. Berlin: Springer-Verlag.

Foken T., 2008b. The energy balance closure problem - an overview. Ecological Applications, 18, 1351-1367.

Fröhlich C., 1991. History of solar radiometry and the World Radiometric Reference. Metrologia, 28, 111-115.

Govindjee (Ed.), 1982. Photosynthesis, Vol. I - Energy Conversion by Plants and Bacteria. In: Cell Biology: A Series of Monographs. Buetow DE, Cameron IL, Padilla GM and Zimmerman AM (Series eds). Academic Press, New York (ISBN: 0122943015).

Gu L., Baldocchi D., Verma S.B., Black T.A., Vesala T., Falge E., and Dowty P.R., 2002. Advantages of diffuse radiation for terrestrial ecosystem productivity. J. Geophysysical Research, 107(D6), 10.1029/2001JD001242.

Gu L., Baldocchi D., Wofsy S.C., Munger J.W., Michalsky J.J., Urbanski S.P., and Boden T.A., 2003. Response of a deciduous forest to the Mount Pinatubo eruption: Enhanced photosynthesis. Science, 299, 2035-2038.

Gueymard A.C., 2018. A reevaluation of the solar constant based on a 42-year total solar irradiance time series and a reconciliation of spaceborne observations. Solar Energy, 168, 2-9. https://doi.org/10.1016/j.solener.2018.04.001

Ibrom A., Jarvis P.G., Clement R.B., Morgenstern K., Oltchev A., Medlyn B., Wang Y.P., Wingate L., Moncrieff J., and Gravenhorst G., 2006. A comparative analysis of simulated and observed photosynthetic $\mathrm{CO}_{2}$ uptake in two coniferous forest canopies. Tree Physiology, 26(7), 845-864.

International Organization for Standardization, 1990a. Solar Energy-Specification and Classification of Instruments for Measuring Hemispherical Solar and Direct Solar Radiation. ISO 9060:1990.

International Organization for Standardization, 1990b. Solar Energy - Field Pyranometers - Recommended Practise for Use. ISO/TR 9901.

International Organization for Standardization, 1992. Solar Energy-Calibration of field pyranometers by comparison to a reference pyranometer. ISO 9847:1992.

International Organization for Standardization, 1993. Solar energy - Calibration of a pyranometer using a pyrheliometer. ISO 9846:1993.
International Organization for Standardization, 1995. Guide to the Expression of Uncertainty of Measurement, Geneva.

International Organization for Standardization, 2008. Quantities and units - Part 7: Light. ISO 80000-7:2008.

ISO 9488, 1999. Solar Energy: Vocabulary.

Johnson F.S., 1954. The solar constant. J. Meteorol., 11(6), 432439, https://doi.org/10.1175/1520-0469(1954)011<0431: TSC $>2.0 . \mathrm{CO} ; 2$

Knohl A. and Baldocchi D., 2008. Effects of diffuse radiation on canopy gas exchange processes in a forest ecosystem. J. Geophysical Res., 113, doi:10.1029/2007JG000663

Lasslop G., Reichstein M., Papale D., et al., 2010. Separation of net ecosystem exchange into assimilation and respiration using a light response curve approach: critical issues and global evaluation. Global Change Biology, 16, 187-208. doi: 10.1111/j.1365-2486.2009.02041.x.

Luo X. and Zhou X., 2006. Soil respiration and the environment. Academic Press, Oxford, Elsevier.

McArthur L.J.B., 2005. Baseline Surface Radiation Network (BSRN) Operations Manual (Version 2.1). World Climate Research Programme, WCRP-121, WMO Tech. Doc. 1274, 176 pp. Geneva

McCree K.J., 1972a. The action spectrum, absorptance and quantum yield of photosynthesis in crop plants. Agric. Meteorol., 9, 191-216.

McCree K.J., 1972b. Test of current definitions of photosynthetically active radiation against leaf photosynthesis data. Agric. Meteorol., 10, 443-453.

McCree K.J., 1981. Photosynthetically Active Radiation, Chapter 2 in Physiological Plant Ecology I: Response to the Physical Environment (Eds Lange O.L., Nobel P.S., Osmond C.B., Ziegler H.) Springer-Verlag, Berlin Heidelberg New York.

Mercado L.M., Bellouin N., Sitch S., Boucher O., Huntingford C., Wild M., and Cox P.M., 2009. Impact of changes in diffuse radiation on the global land carbon sink. Nature, 458, 1014-1017. doi:10.1038/nature07949.

Moffat A., Papale D., Reichstein M., et al., 2007. Comprehensive comparison of gap-filling techniques for eddy covariance net carbon fluxes. Agric. Forest Meteorol., 147, 209-232.

Myers D.R., 1989. Application of a standard method of uncertainty analysis to solar radiometer calibrations. Proc. Annual Conf. American Solar Energy Society, June 19-22, Denver, CO, USA.

Ohmura A., Dutton E.G., Forgan B., et al., 1998. Baseline Surface Radiation Network (BSRN/WCRP): New precision radiometry for climate research. Bulletin of the American Meteorological Society, 79, 2115-2136.

Papale D., Reichstein M., Aubinet M., et al., 2006. Towards a standardized processing of Net Ecosystem Exchange measured with eddy covariance technique: algorithms and uncertainty estimation. Biogeosciences, 3, 571-583.

Perez-Priego O., El-Madany T., Migliavacca M., Kowalski A.S., Jung M., Carrara A., Kolle O., Martín M.P., PachecoLabrador J., Moreno G., and Reichstein M., 2017. Evaluation of eddy covariance latent heat fluxes with independent lysimeter and sapflow estimates in a Mediterranean savannah ecosystem. Agric. Forest Meteorol., 236, 87-99.

Philipona R., Fröhlich C., and Betz Ch., 1995. Characterization of pyrgeometers and the accuracy of atmospheric longwave radiation instruments. Applied Optics, 34(9) 1598-1605. 
Pilegaard K., Ibrom A., Courtney M.S., Hummelshøj P., and Jensen N.O., 2011. Increasing net $\mathrm{CO}_{2}$ uptake by a Danish beech forest during the period from 1996 to 2009. Agric. Forest Meteorol., 151, 934-946.

Quaschning V., 2003. Technology fundamentals. The sun as an energy resource. Renew. Energy World, 6(5), 90-93.

Rabinowitch E.I., 1951. Photosynthesis and Related Processes. vol. II, part 1, Interscience Publ., New-York.

Rebmann C., Aubinet M., Schmid H.P., et al., 2018. ICOS eddy covariance flux-station site setup. Int. Agrophys., 32, 471-494.

Reda I., Hickey J.R., Stoffel T., and Myers D., 2002. Pyrgeometer calibration at the National Renewable Energy Laboratory (NREL). J. Atmospheric and Solar-Terrestrial Physics, 64(15), 1623-1629.

Reda I., Gotseff P. A., Stoffel T., and Webb C., 2003. Evaluation of improved pyrgeometer calibration method. In Proc. Thirteenth Atmospheric Radiation Measurement (ARM) Science Team Meeting (Ed. by D. Carrothers). U.S. Department of Energy, Richland, Washington.

Reichstein M., Tenhunen J.D., Roupsard O., et al., 2002. Severe drought effects on ecosystem $\mathrm{CO}_{2}$ and $\mathrm{H}_{2} \mathrm{O}$ fluxes at three Mediterranean evergreen sites: Revision of current hypotheses? Global Change Biology, 8(10), 999-1017, doi:10.1046/j.1365-2486.2002.00530.x.

Roderick M.L., Farquhar G.D., Berry S.L., and Noble I.R., 2001. On the direct effect of clouds and atmospheric particles on the productivity and structure of vegetation, Oecologia, 129, 21-30.

Ross J. and Sulev M., 2000. Sources of errors in measurements of PAR. Agric. Forest Meteorol., 100, 103-125.

Rutledge S., et al., (2010). Photodegradation leads to increased carbon dioxide losses from terrestrial organic matter. Global Change Biology, 16(11), 3065-3074.

Sitch S., Huntingford C., Gedney N., et al., 2008. Evaluation of the terrestrial carbon cycle, future plant geography and climate-carbon cycle feedbacks using 5 Dynamic Global Vegetation Models (DGVMs), Global Change Biology, 14, $1-25$.
Stoffel T., 2005. Solar Infrared Radiation Station (SIRS) Handbook, Tech. Rep., ARM TR-025, 29 pp., Atmos. Radiat. Meas. Program, U.S. Dep. of Energy, Washington, D. C. (Available at http://www.arm.gov.).

Stoy P., Mauder M., Foken T., et al., 2013. A data-driven analysis of energy balance closure across FLUXNET research sites: The role of landscape scale heterogeneity. Agricultural and Forest Meteorology, 171-172: 137-152. doi: 10.1016/j. agrformet.2012.11.004

Vignola F., Michalsky J., and Stoffel T., 2012. Solar and infrared radiation measurements. Energy and the Environment. CRC Press. New York: Taylor and Francis.

Wehrli C., 1985. Extraterrestrial solar spectrum. Publication No. 615, Physikalisch-Meteorologisches Observatorium Davos + World Radiation Center (PMOD/WRC) Davos Dorf, Switzerland.

Wells C.V., 1995. Optical and Solar Radiometry Standards and Traceability. PV Radiometric Workshop Proc., NREL CP/411-20008. National Renewable Energy Laboratory, Golden, CO.

Wielicki B.A., Young D.F., Mlynczak M.G., Thome K.J., Leroy, S., Corliss J., et al., 2013. Achieving climate change absolute accuracy in orbit. Bulletin of the American Meteorological Society, 94 (10), 1519-1539. https://doi. org/10.1175/BAMS-D-12-00149.1

Wilson K., Goldstein A., Falge E., et al., 2002. Energy balance closure at FLUXNET sites. Agric. Forest Meteorol., 113, 223-243.

World Meteorological Organization, 1983. Guide to Climatological Practices. Second edition, WMO-No. 100, Geneva

World Meteorological Organization, 1990. Abridged Final Report of the Tenth Session of the Commission for Instruments and Methods of Observation (CIMO X). WMO No., 727, Geneva.

World Meteorological Organization, 2005. Baseline Surface Radiation Network (BSRN): Operations Manual. WCRP121. WMO/TD-No. 1274, Geneva.

World Meteorological Organization, 2008. Guide to Meteorological Instruments and Methods of Observation. World Meteorological Organization-No. 8, Geneva. 
Appendix

Table A1. Radiation quantities measured at ICOS ecosystem stations.

\begin{tabular}{|c|c|c|}
\hline ICOS variable name / Acronym & Range & Units \\
\hline Incoming short-wave radiation / $S W \_I N$ & $0-2000$ & $\mathrm{~W} \mathrm{~m} \mathrm{~m}^{-2}$ \\
\hline Outgoing short-wave radiation / SW OUT & $0-2000$ & $\mathrm{~W} \mathrm{~m}^{-2}$ \\
\hline Diffuse short-wave radiation / $S W \_D I F$ & $0-1000$ & $\mathrm{~W} \mathrm{~m}^{-2}$ \\
\hline Incoming long-wave radiation / $L W I I N$ & $50-700 \dagger$ & $\mathrm{W} \mathrm{m} \mathrm{m}^{-2}$ \\
\hline Outgoing long-wave radiation / $L W \_O U T$ & $50-700 \dagger$ & $\mathrm{W} \mathrm{m} \mathrm{m}^{-2}$ \\
\hline Net radiation / NETRAD & $-300-1500+$ & $\mathrm{W} \mathrm{m} \mathrm{m}^{-2}$ \\
\hline Incoming photosynthetic photon flux density / PPFD_IN & $0-4000$ & $\mu \mathrm{mol}$ photons $\mathrm{m}^{-2} \mathrm{~s}^{-1}$ \\
\hline Outgoing photosynthetic photon flux density / PPFD_OUT & $0-4000$ & $\mu \mathrm{mol}$ photons $\mathrm{m}^{-2} \mathrm{~s}^{-1}$ \\
\hline Diffuse photosynthetic photon flux density / PPFD_DIF & $0-2000$ & $\mu \mathrm{mol}$ photons $\mathrm{m}^{-2} \mathrm{~s}^{-1}$ \\
\hline $\begin{array}{l}\text { Below-canopy Photosynthetic photon flux density } \\
P P F D \_B C \_I N\end{array}$ & $0-4000$ & $\mu \mathrm{mol}$ photons $\mathrm{m}^{-2} \mathrm{~s}^{-1}$ \\
\hline
\end{tabular}

* Terminology for meteorological radiation quantities (Annex 7.B, WMO-No. 8, WMO 2008)

$\dagger$ The lower and upper limits for long-wave radiation correspond to black body radiance at $-100^{\circ} \mathrm{C}$ and $60^{\circ} \mathrm{C}$, respectively.

t Expected extreme range has no practical implication for net radiation that is determined as the algebraic sum of the four measured terms: NETRAD $=S W_{-} I N-S W_{-} O U T+L W_{-} I N-L W_{-} O U T$. 
Table A2. ISO and WMO pyranometer classification: Specifications requirements. When ISO and WMO specifications differ, the ISO specifications are listed first, followed by a "/", and then the WMO characteristics.

\begin{tabular}{|c|c|c|c|}
\hline ISO Specifications / WMO Characteristics & $\begin{array}{c}\text { Secondary Standard } \\
\text { / High-Quality }\end{array}$ & $\begin{array}{l}\text { First Class / } \\
\text { Good Quality }\end{array}$ & $\begin{array}{c}\text { Second Class } \\
\text { / Moderate } \\
\text { Quality }\end{array}$ \\
\hline Response time (95\% response) & $<15 \mathrm{~s}$ & $<30 \mathrm{~s}$ & $<60 \mathrm{~s}$ \\
\hline $\begin{array}{l}\text { Zero offset response: to } 200 \mathrm{Wm}^{-2} \text { net thermal } \\
\text { radiation (ventilated) }\end{array}$ & $7 \mathrm{Wm}^{-2}$ & $15 \mathrm{Wm}^{-2}$ & $30 \mathrm{Wm}^{-2}$ \\
\hline $\begin{array}{l}\text { Zero offset response: to } 5 \mathrm{~K} \mathrm{~h}^{-1} \text { change in ambient } \\
\text { temperature }\end{array}$ & $\pm 2 \mathrm{Wm}^{-2}$ & $\pm 4 \mathrm{Wm}^{-2}$ & $\pm 8 \mathrm{Wm}^{-2}$ \\
\hline Resolution (smallest detectable change) & $\pm 1 \mathrm{Wm}^{-2}$ & $\pm 5 \mathrm{Wm}^{-2}$ & $\pm 10 \mathrm{Wm}^{-2}$ \\
\hline Stability (change in sensitivity per year) & $\pm 0.8 \%$ & $\pm 1.6 \% / 1.5 \%$ & $\pm 2.0 \% / 3.0 \%$ \\
\hline $\begin{array}{l}\text { Nonlinearity (deviation from sensitivity at } 500 \\
\mathrm{Wm}^{-2} \text { over } 100 \text { to } 1000 \mathrm{Wm}^{-2} \text { range) }\end{array}$ & $\pm 0.2 \% / 0.5 \%$ & $\pm 0.5 \% / 1.0 \%$ & $\pm 2.0 \% / 3.0 \%$ \\
\hline $\begin{array}{l}\text { Directional response for beam radiation (error due } \\
\text { to assuming that the normal incidence response at } \\
1000 \mathrm{Wm}^{-2} \text { is valid for all directions) }\end{array}$ & $\pm 10 \mathrm{Wm}^{-2}$ & $\pm 20 \mathrm{Wm}^{-2}$ & $\pm 30 \mathrm{Wm}^{-2}$ \\
\hline $\begin{array}{l}\text { Spectral selectivity (deviation of the product of } \\
\text { spectral absorptance and transmittance from the } \\
\text { mean). ISO }(0.35-1.5 \mu \mathrm{m}) / W M O(0.3-3 \mu \mathrm{m})\end{array}$ & $\pm 2 \%$ & $\pm 5 \%$ & $\pm 10 \%$ \\
\hline $\begin{array}{l}\text { Temperature response (error due to } 50^{\circ} \mathrm{C} \text { ambient } \\
\text { temperature change) }\end{array}$ & $\pm 2 \%$ & $\pm 4 \%$ & $\pm 8 \%$ \\
\hline $\begin{array}{l}\text { Tilt response (deviation from horizontal } \\
\text { responsivity due to tilt from horizontal to vertical } \\
\text { at } 1000 \mathrm{Wm}^{-2} \text { ) }\end{array}$ & $\pm 0.5 \%$ & $\pm 2 \%$ & $\pm 5 \%$ \\
\hline Suitable applications & Working standard & $\begin{array}{c}\text { Network } \\
\text { operations }\end{array}$ & $\begin{array}{l}\text { Low-cost } \\
\text { networks }\end{array}$ \\
\hline \multicolumn{4}{|l|}{ Achievable uncertainty* ( $95 \%$ confidence level): } \\
\hline Hourly totals & $\pm 3 \%$ & $\pm 8 \%$ & $\pm 20 \%$ \\
\hline Daily totals & $\pm 2 \%$ & $\pm 5 \%$ & $\pm 10 \%$ \\
\hline
\end{tabular}

*Indicative estimates of the uncertainties of measurements if pyranometers are used with appropriate expertise and quality control (WMO, 2008). The estimated uncertainties are based on the following assumptions: (a) Instruments are well-maintained, correctly levelled and clean; (b) Hourly figures are for clear-sky irradiances at solar noon; (c) Daily exposure values are for clear days at mid-latitudes 
Table A3. Minimum specifications requirements for long-wave radiation sensors (i.e. pyrgeometers) used at ICOS stations.

\section{Sensor Specifications / Characteristics}

Response time (95\% response)

Stability (change in sensitivity per year)

Nonlinearity (from $-200 \mathrm{~W} \mathrm{~m}^{-2}$ to $+200 \mathrm{~W} \mathrm{~m}^{-2}$ )

Temperature response (for a $50^{\circ} \mathrm{C}$ temperature change)

Zero offset response: to $5 \mathrm{~K} \mathrm{~h}^{-1}$ change in ambient temperature

Tilt error

Spectral range (wavelengths where response is greater than 50

$\%$ of maximum)

\section{ICOS requirements}

$$
\begin{aligned}
& <30 \mathrm{~s} \\
& <1 \% \\
& <1 \% \\
& <4 \%
\end{aligned}
$$$$
<4 \mathrm{Wm}^{-2}
$$

$<1 \%$

$4.5-40 \mu \mathrm{m}$

Table A4: Minimum specifications requirements for PAR Quantum sensors used at ICOS stations.

\section{Sensor Specifications / Characteristics}

Response time (95\% response)

Stability (change in sensitivity per year)

Nonlinearity (deviation in sensitivity up to $10^{4} \mu \mathrm{mol} \mathrm{m}^{-2} \mathrm{~s}^{-1}$ )

Directional response error for beam radiation

(Cosine response + azimuthal response)

Temperature response (for a $50^{\circ} \mathrm{C}$ temperature change)

Spectral range (wavelengths where response is greater than 50 $\%$ of maximum)

Field of view

\section{ICOS requirements}

$$
\begin{aligned}
& <1 \mathrm{~s} \\
& <2 \% \\
& <1 \% \\
& <10 \%
\end{aligned}
$$$$
<0.15 \% /{ }^{\circ} \mathrm{C}
$$

$400-700 \mathrm{~nm} \pm 5 \mathrm{~nm}$ 
Table A5. ICOS target uncertainty and estimated measurement uncertainty or target uncertainty in high performance radiation measurement networks.

\begin{tabular}{|c|c|c|c|c|}
\hline & $\begin{array}{l}\text { ICOS } \\
\text { Target }\end{array}$ & $\begin{array}{c}\text { BSRN } \\
1997 \text { Target* }\end{array}$ & $\begin{array}{c}\text { BSRN } \\
2004 \\
\text { Target** }\end{array}$ & $\begin{array}{c}\text { SIRS Measurement } \\
\text { Uncertainty } \dagger\end{array}$ \\
\hline $\begin{array}{l}\text { Incoming short-wave (solar) / } \\
\qquad S W_{-} I N\end{array}$ & $\begin{array}{l} \pm 5 \% \# / \\
\pm 10 \%\end{array}$ & $\begin{array}{l} \pm 2.0 \% \text { or } \\
5 \mathrm{Wm}^{-2}\end{array}$ & $\begin{array}{l} \pm 2.0 \% \text { or } \\
5 \mathrm{Wm}^{-2}\end{array}$ & $\begin{array}{l} \pm 6.0 \% \text { or } \\
10 \mathrm{Wm}^{-2}\end{array}$ \\
\hline $\begin{array}{l}\text { Outgoing short-wave } \\
\text { (reflected) / SW_OUT }\end{array}$ & $\pm 10 \%$ & $\pm 3 \%$ & $\pm 2 \%$ & $\begin{array}{l} \pm 6.0 \% \text { or } \\
15 \mathrm{Wm}^{-2}\end{array}$ \\
\hline $\begin{array}{l}\text { Incoming long-wave } \\
\text { (atmospheric) / } L W_{-} I N\end{array}$ & $\pm 10 \%$ & $\begin{array}{l} \pm 5 \% \text { or } \\
10 \mathrm{Wm}^{-2}\end{array}$ & $\begin{array}{l} \pm 2.0 \% \text { or } \\
3 \mathrm{Wm}^{-2}\end{array}$ & $\begin{array}{l} \pm 2.5 \% \text { or } \\
4 \mathrm{Wm}^{-2}\end{array}$ \\
\hline $\begin{array}{l}\text { Outgoing long-wave } \\
\text { (terrestrial) / LW_OUT }\end{array}$ & $\pm 10 \%$ & $\begin{array}{l} \pm 5 \% \text { or } \\
10 \mathrm{Wm}^{-2}\end{array}$ & $\begin{array}{l} \pm 2.0 \% \text { or } \\
3 \mathrm{Wm}^{-2}\end{array}$ & $\begin{array}{l} \pm 2.5 \% \text { or } \\
4 \mathrm{Wm}^{-2}\end{array}$ \\
\hline Incoming PPFD / PPFD_IN & $\pm 10 \%$ & $N A$ & $N A$ & $N A$ \\
\hline Outgoing PPFD / PPFD_OUT & $\pm 10 \%$ & $N A$ & $N A$ & $N A$ \\
\hline Diffuse short-wave / SW_DIF & $\pm 10 \%$ & $N A$ & $N A$ & $N A$ \\
\hline Diffuse PPFD / PPFD DIF & $\pm 10 \%$ & $N A$ & $N A$ & $N A$ \\
\hline \multicolumn{2}{|c|}{$\begin{array}{l}{ }^{\#} \text { using secondary } \\
\text { standard dedicated } \\
\text { pyranometer }\end{array}$} & $\begin{array}{c}\text { *from WCRP- } \\
64 \\
\text { Nov } 1991\end{array}$ & $\begin{array}{l}* * \text { Estimated } \\
\text { from } \\
\text { measurements } \\
\text { (Mc Arthur, } \\
\text { 2005) }\end{array}$ & $\begin{array}{l}\dagger \text { Estimated from } \\
\text { measurements } \\
(\text { Stoffel, 2005) }\end{array}$ \\
\hline
\end{tabular}

